\title{
Arquivo, corpos difusos e espaços heterotópicos nas tiras da Laerte
}

DOI: http://dx.doi.org/10.21165/el.v50i3.2975

\section{Gilson Costa da Silva'}

\section{Resumo}

Observando transformações do corpo enquanto objeto constituído e atravessado pelos discursos da sexualidade em tiras de cartunistas brasileiros e refletindo acerca dos processos de subjetivação no presente, nosso objetivo geral é analisar a relação corpo-espaço em tirinhas da Laerte, disponibilizadas em seu blog Muriel Total. Para isso, temos como objetivos específicos refletir sobre as categorias de corpo e espaço enquanto complementares; refletir sobre a categoria de arquivo enquanto condiçãoespaço movente; e analisar cada tirinha enquanto síntese-espelho de uma subjetividade, comentário localizado no devir da teia discursiva e nos limites de resistência da história. Teórica e metodologicamente, desenvolvemos uma pesquisa bibliográfica de arquivo de caráter qualitativo em que teoria e objeto dialogam nos termos de uma cartografia histórica da sexualidade a partir dos estudos arqueogenealógicos de Michel Foucault. Além disso, recorremos aos trabalhos de Courtine e Milanez para refletir sobre o corpo e sobre a produtividade da categoria de intericonicidade, da memória das imagens. Nossas considerações finais delineiam uma relação marcada por uma multiplicidade de aspectos e perspectivas sobre o corpo que especificam um modo particular de interação com o arquivo, no ponto em que o corpo e o espaço se cruzam nas novas tecnologias, em novas formas de ser no mundo.

Palavras-chave: corpo; arquivo; intericonicidade; heterotopia; discurso.

1 Universidade Federal de Pernambuco (UFPE), Recife, Pernambuco, Brasil; gilsonsilva884@gmail.com; https://orcid.org/0000-0003-4159-3677 


\title{
Archive, diffuse bodies and heterotopic spaces in Laerte's comic strips
}

\begin{abstract}
Observing body transformations as an object constituted and crossed by the discourse of sexuality in comic strips of Brazilian cartoonists and reflecting on the subjectivation processes in present time, we aim (general) to analyze the body-space relationship in Laerte's comic strips available on her Muriel Total blog. For that, we have to (specifics) (i) reflect about body and space as complementary categories; (ii) reflect about the categories of archive as a moving condition-space; and (iii) analyze comic strips as a mirrorsynthesis from the subjectivity, as a comment located on the to become of the discursive web and in the limits of the resistance of History. Theoretically and methodologically, we developed bibliographic research on qualitative terms, where theory and the subject of the research dialogue on historical cartography about sexuality starting from Foucault's archeogenealogicals studies. Besides that, we resort to Courtine and Milanez's studies to reflect on the body and the productivity of the intericonicity category, which is the image memory category. Our final considerations outline one relationship marked by a multiplicity of aspects and perspectives about the body that specifies a particular way of interaction with the archive, at the point where body and space intersect on new technologies, in new ways of being on the world.
\end{abstract}

Keywords: body; archive; intericonicity; heterotopia, discourse.

\section{Introdução}

A partir de Michel Foucault e seus quatro volumes da História da sexualidade (1984, 1985, 1988, 2018), temos a compreensão de que em nossa sociedade, organizada por instituições que validam ou não dizeres, pode-se observar o aparelhamento mais ou menos incerto de formas de composição, ordenamento e agrupamento dos discursos sobre a sexualidade. A esses contornos mais gerais de estabelecimento para a (des) ordem do discurso (MILANEZ; GASPAR, 2010; FOUCAULT, 1999), podemos chamar de dispositivos e arquivos (FOUCAULT, 2007, 1995; DELEUZE, 2015).

Observamos a existência processual, em condição de devir, contínua, de dispositivos da mídia, da religião, da sexualidade, da lei, das prisões e mesmo da família, mas que não é possível separá-los ou delimitá-los com exatidão (FOUCAULT, 2014), não sem correr o risco de limitar a extensão e os perigos de cada dispositivo e em cada arquivo que se constrói com ele, o que nos faz considerar que o arquivo também se constrói como processo. Nesse contexto, o discurso é pensado em sistemas de dispersão, agrupamentos 
de enunciados ${ }^{2}$ de onde resultam as chamadas formações discursivas (FD), noção marcadamente heterogênea (FOUCAULT, 2007).

Interessa-nos muito precisamente a relação que se pode estabelecer entre os dispositivos da sexualidade e o da mídia na composição de um arquivo possível no presente, na medida em que a sexualidade ainda mantém, enquanto objeto de discurso, o status de tabu no ocidente, incluindo aí o Brasil com sua história problemática com o tema (TREVISAN, 2018; GOMES FILHO, 2016) e, consequentemente, midiatizada pelas novas tecnologias, acentuando os limites heterogêneos do arquivo. Nessa composição íngreme, observamos materialidades diversas transitando entre níveis aparentemente diferentes de institucionalização (MILANEZ, 2006). Cada materialidade se comporta à sua maneira enquanto produção de linguagem com seus modos de subjetivação, ao mesmo tempo unitária e indissociável na (des)ordem do discurso.

Assim, uma enorme teia de discursos (des)organizada se faz perceber e procuramos por dizeres considerados menores, cuja vontade de verdade enfrenta e constitui o comentário, em que relações de poder-saber possam ser observadas por ângulos diferentes e transitórios. Dentre as materialidades lidas em um gesto de leitura inicial, localizamos as histórias em quadrinhos e mais precisamente um subgênero dessas: as tiras ou tirinhas de humor nesse lugar de comentário. Refletindo sobre essas questões, aprofundamonos por meio de uma pesquisa de mestrado. O objetivo era analisar as transformações do corpo enquanto objeto de discurso em tirinhas de cartunistas brasileiros nos últimos quarenta anos.

Aqui, no entanto, enquanto recorte daquela pesquisa, nosso objetivo geral é analisar a relação corpo-espaço em tirinhas da Laerte disponibilizadas publicamente em seu blog Muriel Total (COUTINHO, 2014). Para isso, temos como objetivos específicos refletir sobre as categorias de corpo e espaço enquanto complementares; refletir sobre a categoria de arquivo enquanto condição-espaço movente; e analisar cada tirinha enquanto sínteseespelho de uma subjetividade e comentário (diferente das materialidades discursivas tidas como fundantes de um discurso) localizado no devir da teia discursiva.

2 Situando em pontos estratégicos e precisos, no tratamento da materialidade discursiva em seu nível atômico (FOUCAULT, 2007), isto é, no enunciado enquanto função enunciativa, visível e invisível porque material e difusa, podemos considerar que uma pesquisa sobre o ordenamento dos discursos na relação arquivo-dispositivo tende a estabelecer por base a pergunta de "[...] que singular existência é esta que vem à tona no que se diz e em nenhuma outra parte?" (FOUCAULT, 2007, p. 31). A partir dela, é possível analisar formas de dizer, condições de raridade, regularidade, exterioridade e acúmulo dos enunciados, mas também pelo que escapa a esse dizer-função, seja pela lacuna em relação com a história, seja no distanciamento de um sujeito fundante e sua busca por sentidos ocultos, dos universais. Para além do enunciado, observa-se como dizeres e poderes se relacionam para produzir o sujeito atravessando o corpo enquanto suporte biofisiológico (FOUCAULT, 2013, 2014). 
Teórica e metodologicamente, pensando a partir dos estudos de Michel Foucault e sua arqueogenealogia, desenvolvemos uma pesquisa bibliográfica de caráter qualitativo enquanto estudo de caso em que teoria e objeto se entrelaçam em uma cartografia histórica da sexualidade. Primeiro retomamos os resultados de nossa pesquisa de dissertação, depois recorremos a Deleuze (2015) para pensar a relação dispositivo-arquivo e, então, direcionamos nossas discussões para a relação corpo-espaço, focalizando a materialidade do ciberespaço enquanto heterotopia (MAZZOLA, 2010).

Quanto às análises, considerando as contribuições de Courtine (2010, 2011, 2013a, 2013b), Milanez (2006, 2013) e Milanez e Gaspar (2010) acerca da memória das imagens, buscamos refletir sobre a relação corpo-espaço a partir da categoria de intericonicidade, uma vez que a materialidade escolhida se caracteriza como um gênero textual híbrido. Dada a extensão da presente pesquisa, focaremos em seis tiras, mas devemos considerar a materialidade do suporte blog, pois, é a partir dele que pensamos a noção de espaço.

Por fim, considerando o objetivo geral, nosso problema de pesquisa se especifica por perguntar: como se estabelece a relação corpo-espaço nas tiras do blog Muriel Total da Laerte? Nossa hipótese, advinda das reflexões suscitadas e resultados da pesquisa de dissertação, delineia uma relação marcada por uma multiplicidade de aspectos que especificam um modo particular de interação do arquivo e sua exterioridade com a história.

\section{Pensar pela arqueogenealogia: movimentos cartográficos sobre corpo, espaço e discurso a partir dos dispositivos}

Refletindo sobre a arqueogenealogia foucaultiana como teoria e método em processo, tomamos o termo cartografia para designar nosso empreendimento. Esse termo, deslocado do sentido dicionarizado nos estudos do espaço empírico, toma alguns contornos que viabilizam uma pesquisa que considera todo e qualquer deslocamento do pesquisador em direção e em relação ao objeto, mas, sobretudo, salientando nesse processo a ideia de movimento entre espaços verticais. Em sentido prático, procuramos desenvolver um esforço teórico que se relaciona com um objeto na medida em que esse mesmo objeto modifica a teoria.

Ao discutir sobre a noção de dispositivo segundo a arqueogenealogia, Deleuze (2015) evidencia o trabalho de ruptura acerca da leitura-análise-descrição de arquivo desenvolvido por Foucault. Ao estabelecer as três grandes instâncias, ou linhas (caminhos do pensar, movimentos reflexivos) de seu trabalho, isto é, o poder, o saber e o si, o filósofo especificou que elas não possuem contornos definidos, sendo possível observar, no entanto, que elas estão submetidas a mudanças, "variações" (DELEUZE, 2015). Assim, trabalhar sobre os dispositivos está em considerar essas linhas em termos de sedimentação, mas também fissura e fratura. "Desenredar as linhas de um dispositivo, em cada caso, é construir um 
mapa, cartografar, percorrer terras desconhecidas, é o que ele chama de trabalho sobre o terreno." (DELEUZE, 2015, p. 85), sendo que o primeiro resultado desse movimento é justamente o pesquisador se movendo através dessas linhas. Ele mesmo parte desses conjuntos múltiplos, multilineares.

Para desenvolver esse movimento, então, primeiro devemos observar o objeto em um estado anterior e o que ele produz em termos de deslocamento, o que deixou escapar.

Em nossa pesquisa de mestrado (SILVA, 2019), estabelecemos como objetivo analisar transformações do corpo enquanto objeto dos discursos da sexualidade em tirinhas de cartunistas brasileiros nas últimas quatro décadas, enfatizando a reflexão acerca do sujeito no presente e dos processos de subjetivação em movimento. Para isso, direcionando nossas discussões em direção à relação estabelecida entre as tirinhas e os dispositivos da sexualidade e da mídia, realizamos recortes dos trabalhos de Laerte e Henfil.

A escolha em desenvolver nossa pesquisa com esses dois autores, compreendidos inicialmente como função-autor, segundo Foucault (2007), deu-se na medida em que falar de sexualidade no Brasil no presente nos parece indissociável de sua história recente, o que implica inicialmente pensar em produções que se permitem ser retomadas e atualizadas, que tiveram ou têm alcance de público, por estarem fortemente marcadas pela autoria fazendo parte da história como figuras associáveis no imaginário, mas também por estarem produzindo comentários sobre como o Brasil vivencia a diversidade sexual.

Nossos resultados, por sua vez, nos levaram a observar que o corpo, como discurso (devir) e atravessado por discursos (histórico) da sexualidade, multiplicava-se mesmo que contornado por formações discursivas temporalmente próximas, mas não totalmente correspondentes. Isto dito, encontrávamo-nos diante de diferentes ângulos e diversas perspectivas do corpo, em diferentes corporalidades. Por meio da leitura, enquanto atividade produtora de subjetividade, víamos confluir não apenas o corpo na materialidade dos quadrinhos, mas para além do espaço traçado. Assim, observamos o corpo do autor, o corpo do leitor, o corpo do pesquisador e os corpos comentados e representados pelo desenho, que, em síntese, transformam-se, multiplicam-se e tornam-se difusos ${ }^{3}$. A partir

3 Confluência dos corpos como corpo disciplinado, corpo religioso, corpo condenado, corpo doente, corpo viril, corpo violentado, corpo policial, corpo masculino, corpo monstruoso, corpo feminino, corpo diferente, corpo desviante, corpo normal, corpo patológico, corpo transexual, corpo gay, corpo bissexual, enfim, corpo LGBTIA+, corpo gordo, corpo magro, corpo potente, corpo de resistência. Aliás, no nível do comentário, observamos uma luta entre um corpo sem sexualidade (construído discursivamente pela negação) e um corpo que se enxerga como corpo dotado de sexualidade, corpo devir. 
disso, enfatizando o efeito de comentário das tiras, definimos aquelas materialidades enquanto espelhos-síntese, pois, a cada nova leitura, a memória pessoal mergulhava nas redes lacunares da memória social e produzia efeitos de sentido reatualizados, enquanto possibilidade e acontecimento, recolocando sempre um já dito em relação com um efeito de potência, como devir.

Considerando que o corpo atravessado pela sexualidade se multiplicava dentro e fora das tirinhas, justificando também a dificuldade de tomar a sexualidade como um objeto fechado (FOUCAULT, 2014), um questionamento se acentua: há, sobretudo, a questão do espaço. Em nossa dissertação, mesmo ao tratar da noção de heterotopia, isto é, da justaposição de lugares e espaços, fazíamos isso observando como a realidade empírica era projetada em cada tirinha, como os personagens desenhados moviam-se em poucos quadros e projetavam-se entre o Nordeste da seca dos anos 80 e o Sul da fita adesiva (no trabalho de Henfil), entre espaços proibidos e rituais, de banheiros a outdoors (no trabalho de Laerte) $)^{4}$.

No entanto, indo além e observando que o efeito de multiplicação dos corpos não se dá apenas em relação com os corpos dos personagens, mas com o autor (LAERTE-SE, 2017; HENFIL, 2016 [1978]), o leitor e o pesquisador, os espaços também se multiplicam entre a virtualidade da produção de linguagem e o mundo empírico. Disso resulta a necessidade de se olhar para um terceiro espaço: o ciberespaço, funcionando como um mundo não apenas paralelo, mas extremamente presente, o virtual como o que se confunde ou simplesmente expande a realidade. Considerando, então, que esse efeito se mostra precisamente com a obra da Laerte, realizamos em um novo recorte, focalizamos o blog Muriel Total (COUTINHO, 2014), dada a sua materialidade.

4 Víamos nas tiras de Henfil (1971-1980, 1993) um corpo marcado pela ditadura, um corpo de suplícios, corpos como sexualidade fraturada, um corpo da ditadura: marcado, ferido, disciplinado, amputado, traumatizado, violento, muito embora escapando sempre, como no caso da personagem da Graúna, que se utiliza do discurso da mulher histérica para combater o discurso institucionalizado acerca do papel da mulher, mesmo considerando que o autor ironizasse certas lutas, sinalizando um duplo atravessamento; ou como no caso do Fradim, isto é, um representante religioso que desvirtua a ordem vigente, inclusive tendo sua primeira aparição completamente nu, e sempre se apresentando como alguém sem ética. Além dele, podemos pensar o Cumprido, seu companheiro, e inúmeras vezes sinalizado como um homossexual enrustido que estranhamente se resume a uma piada sobre a ordem institucionalizada e sua hipocrisia, a figura do cidadão de bem, mas também sobre a própria homossexualidade como condição indesejada independentemente dos grupos políticos naquele momento (SILVA, 2018; TREVISAN, 2018). Do outro lado, mas sem traçar paralelos ou comparações, apenas observando mutações dos olhares e discursos, no caso da Laerte (COUTINHO, 2014, 2016, 2020), observamos um corpo dotado de sexualidades, potente, vivo, alegre, paradoxalmente marcado, voltado não apenas para uma imagem positiva da diversidade sexual e de gênero, isto é, das identidades como diferentes, mas da desconstrução dos rótulos. No Manual do Minotauro (COUTINHO, 2020), a cartunista abandona o trabalho com personagens, movimento de desconstrução pela aceitação no jogo entre identidades e indeterminação. 
Para realizar esse novo movimento cartográfıco, precisamos, então, discutir o que entendemos por discurso em relação a um dispositivo produzindo o arquivo.

Remontando ao trabalho metodológico de Foucault, na Arqueologia do Saber (FOUCAULT, 2007), o filósofo defende uma noção que permite ao discurso ser pensado como um sistema de dispersão em si, como um conjunto impreciso de enunciados. No nível do enunciado, o discurso é material, concreto, porque toma formas e meios de se reproduzir, mas invisível porque suas ligações e relações não respondem a nenhum esquema arquitetônico fechado. Entre relações de poder e relações de saber, o discurso se torna um campo de relações estratégicas onde a vontade de verdade funciona sempre imprecisa, mas sistematizada.

Um dispositivo (antes pensado como positividade), por sua vez, englobando discursos, dizeres, relações de poder-saber, corpos e instituições, organiza e viabiliza a possibilidade de existência do arquivo enquanto condições de existência histórica de cada enunciado possível (FOUCAULT, 2007). Entende-se como composição incerta a ideia de que tanto arquivo como dispositivos não são passíveis de serem separados ou delimitados com exatidão. Tratar o discurso a partir deles está em considerar a descontinuidade como princípio ordenador (DELEUZE, 2015), sinalizando, mais uma vez, um tipo descontínuo de cartografia acerca de terrenos íngremes.

Segundo Deleuze (2015, p. 83), um dispositivo seria aquilo que, concretamente, muito precisamente se pode definir como "[...] um conjunto multilinear composto por linhas de natureza diferentes [...]". Diferentemente dos outros sistemas quando tratados como homogêneos e universais, tais como, o sujeito ou a linguagem, o dispositivo funciona primordialmente pela ideia de que qualquer linha pode ser quebrada e que, como já salientamos, marcada por variações.

Realizando uma incursão por meio da arqueogenealogia a partir de Foucault (2007), Deleuze (2015) especifica que o olhar sobre o dispositivo comporta algumas dimensões, sendo duas as principais: curvas de visibilidade e curvas de enunciação. Os dispositivos são como "[...] máquinas de fazer ver e fazer falar [...]" (DELEUZE, 2015, p. 84)5. Além dessa

5 Enquanto máquina de fazer ver, seu funcionamento se dá por focos de luz, linhas de luz que não iluminam objetos pré-existentes, mas que os apagam ou fazem desaparecer na ordem do discurso. Enquanto máquina de dizer, seu funcionamento se especifica por ser enunciado, isto é, a alguém é dado o poder de dizer para o que vem um dispositivo, de onde se é medido ou permitido falar, a exemplo das leis que especificam um indivíduo como culpado ou inocente. Isto dito, todo dispositivo é objeto de explicação, além de poder estabelecer lugares de fala, dizeres e verdades de um momento dado. Considerando que são perceptíveis apenas quando se suspendem os universais, cabe considerar que "[...] não são nem sujeitos nem objetos, mas regimes que é necessário definir pelo visível e pelo enunciável, com suas derivações, as suas transformações, as suas mutações." (DELEUZE, 2015, p. 85). 
divisão complementar, haveria no seu interstício linhas de força e linhas de subjetivação (DELEUZE, 2015). Acerca das linhas de força, compreende-se nela toda a discussão sobre a noção de poder, ou mais precisamente, dos micropoderes, funcionando sempre de forma difusa, pulverizada, mas não puramente caótica. Acerca das linhas de subjetivação, em correlação com os micropoderes, compreendidas como uma nova dimensão do projeto arqueogenealógico, especificam-se pela ideia de que a subjetividade se dá como um processo difuso, "[...] é uma linha de fuga, escapa às outras linhas, escapa-se-lhes. 0 'si próprio' (Soi) não é nem um saber nem um poder [...] uma espécie de mais-valia [...]" (DELEUZE, 2015, p. 87). A (o processo de) subjetivação, assim, corresponderia às regras de conduta da sociedade ateniense, por exemplo, regras (obrigatórias ou não) que fazem o indivíduo refletir sobre si, um cuidado de si. Além desses desdobramentos, para Deleuze (2015), é imprescindível que qualquer olhar sobre os dispositivos, por consequência, mantenha em suspenso qualquer sentido de universal, além de não tratar esse trabalho sobre a criatividade potente como um retorno ao novo. Para Foucault (2007), interessaria, sobretudo, as regularidades.

Por fim, acerca da relação entre dispositivo e arquivo, segundo Deleuze (2015, p. 93), "[...] pertencemos a dispositivos e neles agimos.". A sua atualidade permite-nos dizer o que somos, sendo, no entanto, preciso "[...] distinguir o que somos (o que não seremos mais) e aquilo que somos em devir: a parte da história e a parte do actual." (DELEUZE, 2015, p. 93). O arquivo corresponde à história, é o desenho do que somos e o que deixamos de ser; o actual, por sua vez, é um esboço em transformação. Remetendo à discussão sobre arquivo em Foucault (2007), essa distinção nos leva a pensar que arquivo e dispositivo, mais uma vez, não se separam, não podem ser descritos por inteiro, são difusos. Pelo dispositivo, observamos o que somos enquanto devir, pelo arquivo, observamos o que somos e deixamos de ser. Pensando do ponto de vista metodológico, analisar ou organizar um arquivo é sempre trabalhar com a lacuna, um exercício cartográfico.

Voltando-nos para nosso objeto e as relações que procuramos estabelecer, perguntamonos: mas e a mídia? Como pensar em um dispositivo da mídia formando arquivos sobre sexualidade? E as tiras? Inicialmente, convém observar que a mídia, que não é a Grande Mídia (que supõe ter 'consciência') ou apenas os meios de comunicação (parte técnica), enquanto poderoso e complexo dispositivo de produção de discurso (MILANEZ, 2006), (auto)autorizada a falar sobre a sexualidade, funciona medindo-a, dividindo-a ou homogeneizando-a, no e sobre o corpo nos termos de uma biopolítica, isto é, na carne e além dela, dizeres possíveis (éticos ou não) no limiar aparente entre o privado e o público. Isso remete muito precisamente às duas instâncias antes discutidas com suas linhas de luz (ou visibilidade) e linhas de enunciação. Para nós, é importante abordar esse efeito (aparente) de homogeneidade dos poderes e heterogeneidade de saberes, pois é a partir dele que podemos observar o emparelhamento de diversos saberes, poderes e vontade de saber, enfim, enunciados regulares que se revestem para constituir as diversas vontades de verdade no presente. Multiplicação de focos de luz, multiplicação de dizeres, aparente neutralidade enquanto data, informação. 
Sabemos, no entanto, que essa especificação não se reduz única e exclusivamente a isso, que esse funcionamento, em sua complexidade, tem sido motivo de estudo ele mesmo. Sabendo da existência de uma quantidade expressiva de trabalhos sobre a mídia enquanto dispositivo que age sobre o sensível ou comum, completando-o como em uma forma de bios-virtual (SODRÉ, 2014; LUHMANN, 2005; MANOVICH, 2001; LIPOVETSKY; SERROY, 2015). Em outro momento, devemos realizar incursões por essas discussões. Considerando essa complexidade, devemos focar nossos esforços na reflexão de como esse funcionamento se reflete em pontos menores, no estabelecimento de um arquivo, marcadamente histórico, difuso e movente. Neste momento, parece-nos produtivo precisamente pensar o ciberespaço, isto é, a espacialidade do dispositivo midiático na contemporaneidade, como heterotopia, realizando um novo movimento de nossa cartografia. Mas como pensar dessa forma? Como enxergar uma relação entre o ciberespaço como heterotopia na extensão dessa lógica do dispositivo da mídia? Precisamos pensar na materialidade dos espaços em relação com as novas tecnologias. Para compreendermos essa relação, podemos retomar Foucault (2013) a fim de apresentar a noção e retomar o trabalho de Mazzola (2010), que nos parece ter realizado uma aproximação profícua da questão.

De modo geral, a noção de heterotopia se configura pela justaposição de espaços diferentes ou similares, isto é, pela ideia de que espaços se relacionam e se intercambiam, processo de existência em continuidade e intercessão. Para Foucault (2013), uma heterotopia opõe-se inicialmente às utopias como as conhecemos e as descrevemos, isto é, a esses lugares sem lei, lugares dos sonhos, impossíveis de serem rastreados. Planetas que nascem na cabeça do ser humano, diferentes pela individuação. No entanto, não vivemos em espaços vazios, neutros e planos. Encontramo-nos atravessados, localizados. Vivemos em espaços possíveis de medir (ao menos, aparentemente) e especificar, cartografar (FOUCAULT, 2013). Para além desses lugares, há aqueles que são diferentes em tudo desses tipos. As heterotopias são utopias reais, possíveis de serem encontradas e se ligam aos espaços geográficos como forma de apagá-los, neutralizálos ou purificá-los (FOUCAULT, 2013). São como contra espaços.

Citando a disciplina que estudaria as heterotopias, a Heteropologia, Foucault (2013) discute cinco princípios para seus estudos ${ }^{6}$. Segundo Foucault $(2013$, p. 30), todos esses

60 primeiro (FOUCAULT, 2013) especifica-se pelo argumento de que não existe uma sociedade sequer que não produza suas próprias heterotopias, considerando, no entanto, que essas não correspondem a esquemas fechados no sentido de que são simplesmente reproduzidas por outras sociedades. Nesse sentido, seria possível observar e classificar as sociedades a partir dos tipos que preferem, sendo as mais comuns as heterotopias de crise (biológicas) e de desvio. 0 segundo princípio (FOUCAULT, 2013) especifica-se pelo argumento de que qualquer sociedade, no transcorrer da sua história, pode fazer com que suas heterotopias se diluam e se refaçam, isto é, podem desaparecer, serem criadas e mesmo reposicionadas. O cemitério como exemplo, segundo o autor, marcando muito precisamente o lugar-outro, modificou-se: antes no centro das cidades, 
princípios se juntam a considerar uma ideia geral: as heterotopias são a contestação de todos os outros espaços. Ligam-se ao real e o desconstroem, a exemplo das colônias, sempre tidas no imaginário dos que as buscavam como melhores do que a terra natal. Nesse sentido, podemos observar o barco. O barco é fechado em si, mas se liga a todos os lugares, "[...] é a heterotopia por excelência." (FOUCAULT, 2013, p. 30).

Navegar, acessar, estabelecer links. Não nos parece estranho que as ações no ciberespaço se caracterizem diretamente como essa metáfora. Mazzola (2010) realizou uma pesquisa muito precisa acerca dessa relação tão familiar. Para o autor, trabalhando sob a ótica da Análise do Discurso (AD) Francesa de linha pecheuxtiana em contato com os trabalhos de Foucault e teóricos da comunicação, como Levy (1996), no mundo moderno contemporâneo, tudo se virtualiza, real e virtual se aproximam e se desterritorializam. 0 ciberespaço, nesse sentido, expande-se exponencialmente, o tempo se altera, resultando em novas e diferentes práticas sobre o ser. "Como viver sem e-mail? Como deixar de usar o computador para trabalhar? Quem somos nós hoje, sem as máquinas?" (MAZZOLA, 2010, p. 54). Primordialmente, a existência no interior desse processo implica virtualização, digitalização e meios de acesso.

O tratamento da internet como um espaço, segundo Mazzola (2010, p. 55), direciona o olhar para a ideia de um lugar impossível, mesmo intervindo tão fortemente no espaço geográfico, como um lugar de atualizações, conexões, nós. A diferença maior, no entanto, está na sua materialização como projeção, "[...] materializa-se em uma tela." (MAZZOLA, 2010, p. 56). No entanto, ainda segundo o pesquisador, o ciberespaço não apenas realiza em si ou projeta a confluência de sons, imagens (fixas ou em movimento) e textos. É também característica do ciberespaço produzir locais de afecção e interação, tais como, "[...] locais de relacionamentos, resgate de afetividade, de arquivamento, de memória, de representações icônicas, de encontros, de trocas, de viagem, de conhecimento, de ausência de regras, de coisas inúteis [...]" (MAZZOLA, 2010, p. 56-57). Não apenas sobreposição, mas interconexão, links.

depois nas beiradas. O terceiro princípio, por sua vez, trata da observação de que, em geral, as heterotopias justapõem espaços incompatíveis em termos de natureza, a exemplo dos teatros e jardins persas (FOUCAULT, 2013). O quarto princípio diz respeito ao tempo. As heterotopias se ligam a recortes singulares de tempo, parentes de heterocronias (FOUCAULT, 2013). As formas como elas se ligam ao tempo, por sua vez, especificam-se por três formas mais comuns: aquelas que suspendem o tempo, anulam-no e apagam-no (cemitérios, museus); aquelas que se especificam como festas, isto é, suspendem o tempo, mas não o anulam (feiras, festas, colônias de férias); e há as heterotopias que funcionam como lugares de transformação, de regeneração (prisões). O quinto princípio compreende que toda heterotopia possui um sistema de fechamento e/ou abertura (FOUCAULT, 2013). Nesse sentido, remetendo às linhas de luz e enunciação do dispositivo, uma heterotopia sempre se organiza para permitir aos sujeitos adentrarem ou não suas linhas, seja por um sistema totalmente fechado, seja totalmente aberto, ou apenas a alguns iniciados. 
Por fim, considerando que todos os espaços são impregnados de memória e imaginário, Mazzola (2010, p. 58) salienta a importância de se pensar a ideia de "imaginário". Segundo o autor, remetendo à discussão sobre pré-construído e interdiscurso nos termos da AD de Pêcheux (2009), teríamos, no caso do ciberespaço, a impressão de que algo fala anteriormente e em outro lugar.

Para nossa pesquisa, tais questões reverberam na funcionalidade do blog, um espaço heterotópico desde a sua proposta como diário eletrônico (um diário aberto), isto é, um espaço que se supõe definido, tendo um endereço, mas que, em seu funcionamento como arquivo, simula um espaço outro a todo momento, como memória e afeto.

\section{Arquivo movente, corpos difusos e espaços heterotópicos em tiras}

Realizando a análise do blog Muriel Total (COUTINHO, 2014), com publicações entre 2009 e 2014, isto é, entre a abertura para o público do processo de mudança de identidade de gênero da cartunista Laerte e a sua decisão de não utilizar mais personagens específicos, surge como um recurso para organizar e disponibilizar no âmbito da internet um conjunto de produções, funcionando como um espaço de memória (uma escrita de si), como um arquivo fechado em si pela autoria e pelo tema. Nele estão contidas todas as tirinhas da personagem Muriel, uma mulher transexual, sendo que essas tiras foram anteriormente publicadas no caderno de informática do jornal A Folha de São Paulo. Aliás, a esse anteriormente nos referimos também ao personagem Hugo (COUTINHO, 2005), que tratava geralmente de questões sobre informática e seus impactos no cotidiano, tais como no trabalho ou nos relacionamentos. Para nós, é importante observar que o Hugo reaparece em algumas tirinhas da Muriel no blog, mas sempre em relação a, como o outro, isto é, de um atual para um efeito do pré-construído. Em outras palavras, antes da Muriel havia Hugo, mas Hugo vai desaparecendo conforme as dúvidas, e experimentações da Muriel levam-na a desconstruir alguns binarismos sobre si e sobre o perigo dos rótulos.

Para quem tem aproximação afetiva, isto é, para o corpo que potencializa os efeitos das linhas de subjetivação com as quais se depara na leitura das tirinhas, com o trabalho da cartunista, é possível traçar um paralelo, inclusive temporal, entre o processo pessoal (corpo da autora) da Laerte como pessoa trans e a sua personagem. Nesse sentido, temos a ideia de que as tirinhas sobre a Muriel comentam algo que se espelha pela figura pública da Laerte. Essa observação, de forma mais direta, é permitida a partir do filme Laerte-se (2017), uma produção intimista que desconstrói positivamente a figura pública e permite ao público adentrar os questionamentos da cartunista. Mas é preciso observar que na mesma medida em que se propõe um espaço público, isto é, aberto à consulta e fechado em si mesmo, espaço de memória que não comporta outros focos de luz, esse blog dialoga com a noção de heterotopia como a compreendemos anteriormente. O motivo é simples, pois, na medida em que as tirinhas, enquanto espelhos-síntese, multiplicam os corpos comentados, os espaços se agregam e produzem uma relação heterotópica 
em dois níveis: na representação em cada tirinha e no blog como confluência desses comentários. Pensando na metáfora do barco, heterotopia por excelência, e mesmo o jardim, o blog funciona como lugar de encontro remontando um complexo processo de identificação focado nas questões de identidade de gênero a partir da memória das imagens, relações de intericonicidade.

De maneira geral, partindo de Courtine (2010, 2011, 2013a, 2013b), Milanez $(2006,2013)$ e Milanez e Gaspar (2010), trabalhando sobre o enunciado, o interdiscurso e a memória discursiva, essa noção comporta duas informações importantes sobre memória das imagens: primeiro, que toda imagem, enquanto materialidade discursiva, pode ser relacionada a conjuntos em que formas, cores e formatos compõem parte do imaginário de uma cultura possível e produzem enunciados outros em regimes de repetibilidade; segundo, embora comportando conjuntos do imaginário social, toda imagem, seja por meio de uma leitura cotidiana ou em uma discussão acadêmica, encontra-se sempre marcada pelo imaginário pessoal de cada indivíduo, no corpo e para além dele, comporta as próprias imagens que cada um guarda, instância antropológica que permite ao pesquisador poder relacionar uma imagem (função enunciativa) a uma série.

Assim, o que passamos a chamar de síntese-espelho corresponde a um enunciado iconográfico que comporta, de modo geral, essas duas dimensões, da memória e do imaginário geral de uma cultura e da memória pessoal do leitor-pesquisador. No caso das tirinhas, o contato entre essas duas instâncias produz os efeitos de sentido comuns ao gênero (efeito humorístico), sendo a síntese o imaginário de uma linha de subjetivação, e o espelho o processo de reflexão pelo qual o sujeito que lê se subjetiva. Para nós, ler uma tirinha não é diferente de olhar o mundo através de um espelho, portanto, coloca-nos diante de nossa atualidade. Vejamos na prática como isso funciona.

Tirinha 1 - Ouverture
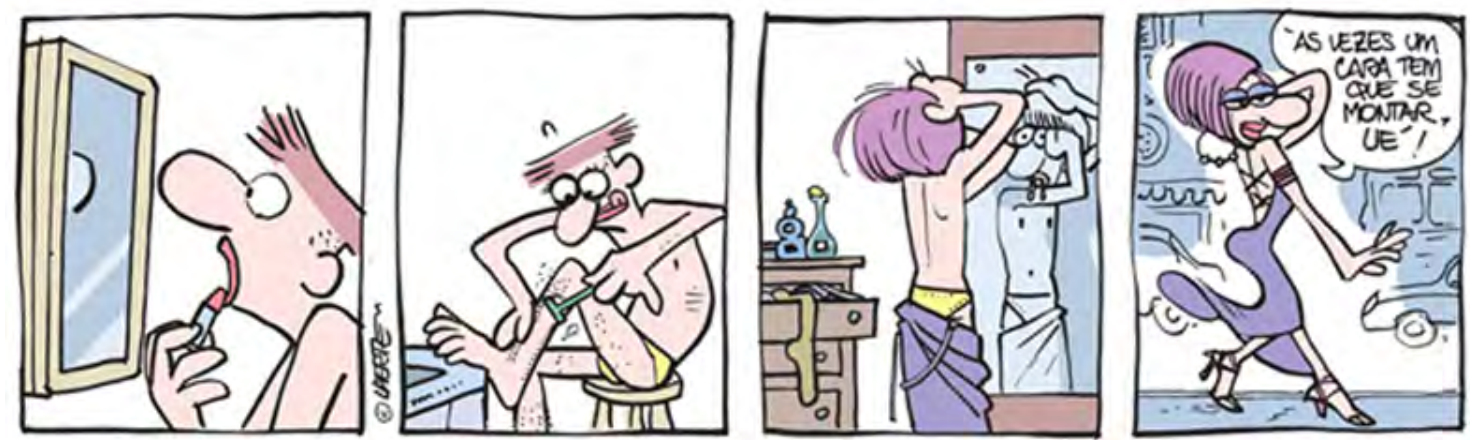

Fonte: Coutinho (2014)

7 Os termos utilizados correspondem aos marcadores de cada tirinha no blog, às palavras-chave. 
Tirinha 2 - Jogos
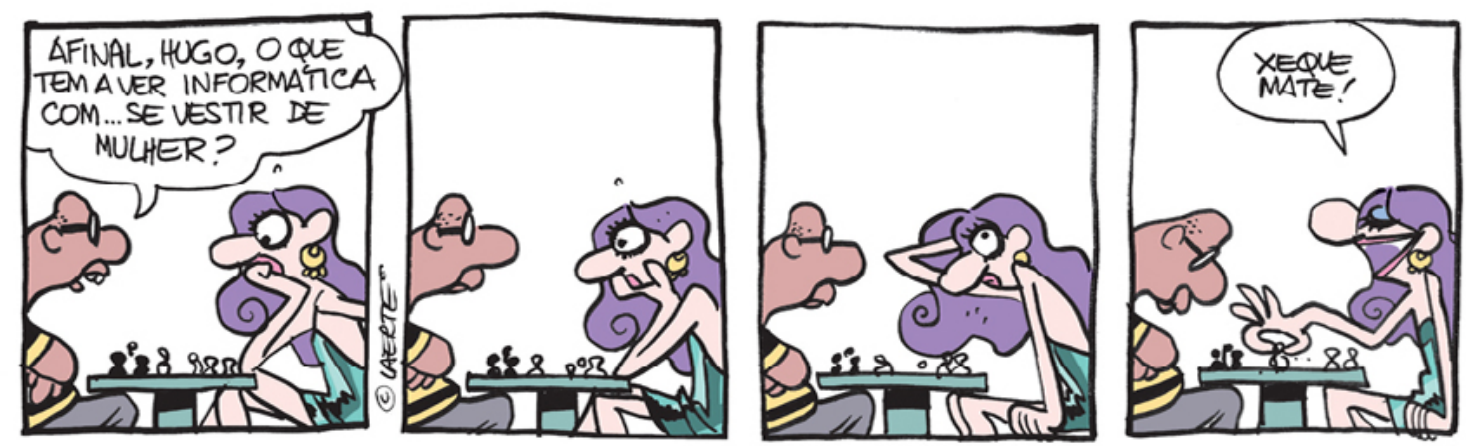

Fonte: Coutinho (2014)

Tirinha 3 - Spam

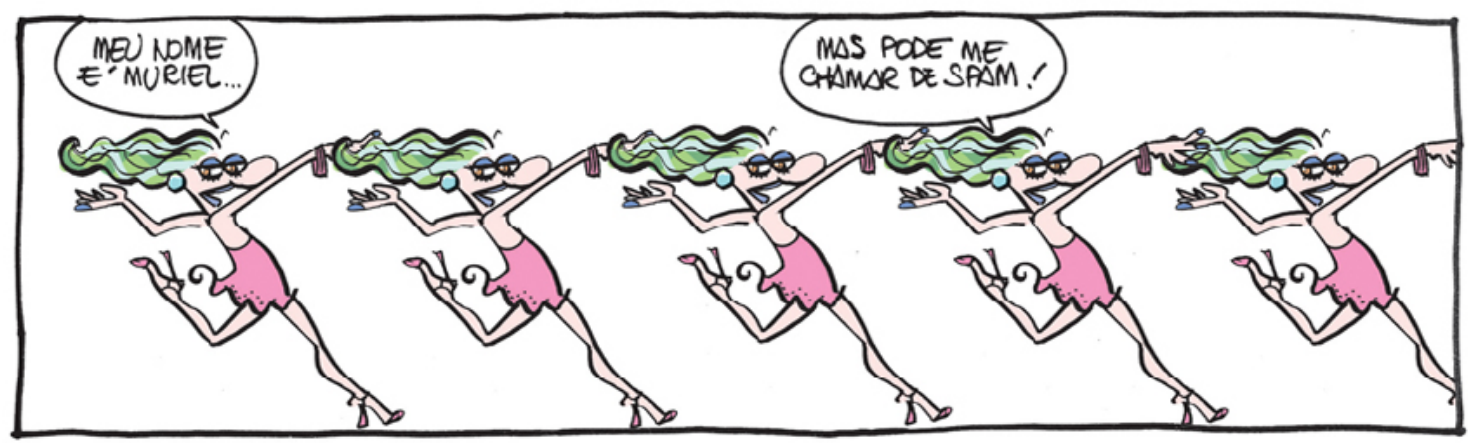

Fonte: Coutinho (2014).

Tirinha 4 - Vírus

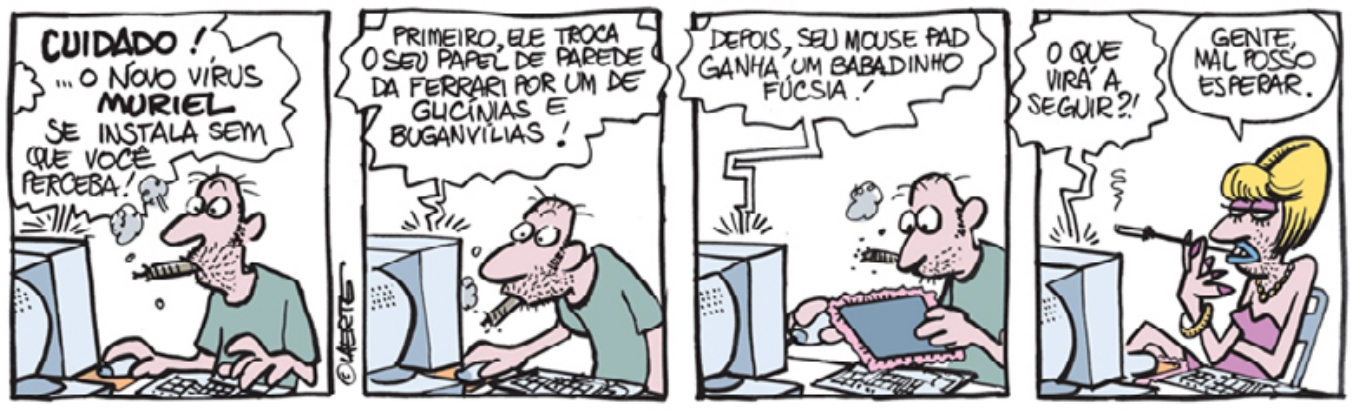

Fonte: Coutinho (2014) 
Tirinha 5 - Travestilidade

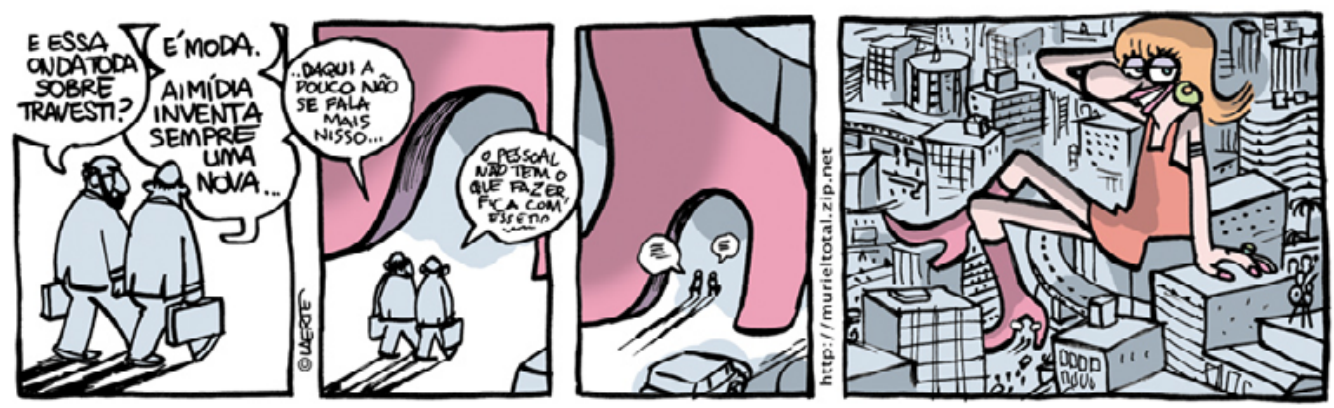

Fonte: Coutinho (2014)

Tirinha 6 - Encontro

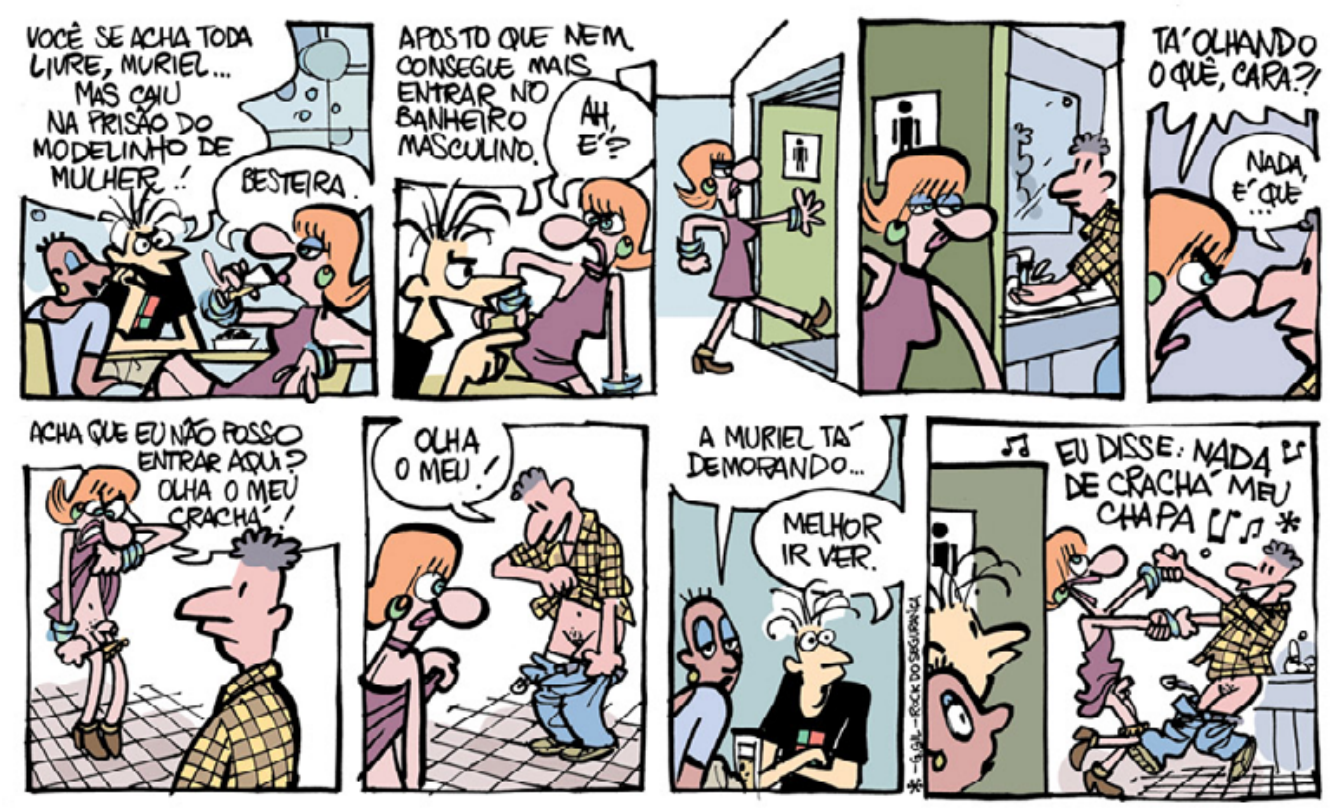

Fonte: Coutinho (2014)

Bem, inicialmente, precisamos considerar não apenas que cada tirinha apresentada corresponde a uma publicação individual dentro do blog, mas a conjuntos menores, séries/ narrativas sobre temas diversos. Assim, observamos uma sequência de publicação, mesmo que não sejam sequências diretas. Por exemplo, as tirinhas 1-4 estão em uma narrativa separada de vinte tirinhas, a número 5 está em uma narrativa de quatro tirinhas. A tirinha 6, por sua vez, estava disposta como a última tirinha do blog.

Essa primeira observação corrobora com nossa discussão sobre a relação dispositivoarquivo na medida em que nos oferece uma rede de associações entre enunciados. Não se trata de qualquer enunciado, mas do estabelecimento de focos de luz e enunciação. Cada 
tirinha, como síntese-espelho, coloca-nos diante de linhas de subjetivação, do imaginário comum, da memória e da história, sobre o tema da sexualidade, seja referenciando, simulando ou refletindo um acontecimento ${ }^{8}$. Do ponto de vista do leitor, desdobramentos acerca das linhas de leitura se mostram.

Quanto ao imaginário social e à memória das imagens, temos, respectivamente: (1) o processo de descobrimento da identidade de gênero como diferença; (2) questionamentos acerca da permissão aparente diante da mudança; (3) metáfora espacial e do corpo relacionando o imaginário das sexualidades e da informática; (4) imaginário do desconhecimento e da patologia; (5) imaginário da homofobia; (6) imaginário dos rótulos em desconstrução.

Do lado antropológico, do corpo do leitor-pesquisador, por sua vez, observamos um corpo refletindo acerca desses imaginários em um questionamento geral: acerca das fraturas e dificuldades em se desvencilhar a diversidade sexual de todo e qualquer binarismo reducionista.

Do lado das linhas de subjetivação, temos apresentadas, respectivamente: (1) a experiência da mudança como processo; (2) a confusão dos discursos sobre os espaços heteronormativos; (3) e (4) a diversidade como algo que se multiplica; (5) a diversidade como algo que preenche todos os espaços; e (6) é possível resistir aos binarismos e rótulos.

Por fim, quanto à relação corpo-espaço, temos que: (1) o corpo dotado de sexualidade ${ }^{9}$ em relação ao primeiro contato com o espaço público, a rua como metáfora do mundo; (2) corpo dotado de sexualidade e os espaços permitidos; (3) corpo dotado de sexualidade multiplica-se para todos os espaços possíveis, virtualiza-se; (4) corpo dotado de sexualidade e espaço privado; (5) corpo dotado de sexualidade e espaço público, visível e invisível; (6) desconstrução dos corpos para além dos espaços.

Portanto, devemos observar que todas as materialidades funcionam em termos de justaposição. Temos um corpo que se justapõe ao espaço público, fruto do imaginário construído acerca das diferenças; temos as justaposições do corpo e dos espaços privados; e temos a justaposição do virtual e do material (como dito, que também se interliga ao próprio funcionamento do blog) em temos de espaço.

8 Em outras tirinhas, encontramos referências a acontecimentos recentes acerca da chamada ditadura gay, da cura gay, da Parada LGBTQIA+.

9 Nesse e nos demais casos, há o foco no corpo transexual. No entanto, podemos pensar em um corpo LGBTIA+, uma vez que muitos desses processos são vivenciados em menor ou maior grau por diferentes indivíduos que se identificam como LGBTIA+. 


\section{Considerações finais}

Como vimos, é parte do processo de existência dos dispositivos e das heterotopias deixar de ser, deixar de funcionar ou se transformar. Isso se reflete no arquivo construído e nos processos de subjetivação que ali se formam e circulam. O enunciado, por sua vez, se repete em outros lugares e em relação a outros imaginários.

No caso do blog, esse diário virtual não é diferente. Na época do domínio das redes sociais, um perfil no Facebook pode se mostrar mais próximo do leitor do que um link para uma página de um domínio diferente. Evidencia-se a rapidez da leitura e do acesso a ela, o tempo se esfacela. No processo de escrita desta pesquisa, deparamo-nos com um caso assim. Ao direcionarmos o cursor para o link do blog Muriel Total, deparamo-nos com uma mensagem de que a página tinha ido para o espaço, isto é, teria sido fechada, estava indisponível. Não convém a nós, pesquisadores, debruçarmo-nos sobre os motivos para sua descontinuação. Resta-nos, então, apenas evidenciar o caráter histórico de nossa pesquisa e do arquivo que se liquefaz no espaço heterotópico do ciberespaço. Cartografar sobre lugares íngremes, mais uma vez, olhar o que somos deixando de ser.

Como resultado, confirmarmos nossa hipótese da multiplicação da relação corpoespaço. Enquanto arquivo, o blog Muriel Total marca seu lugar na história da sexualidade no Brasil, mesmo quando deixa de ser um lugar acessível, recuperável apenas por notícias e pesquisas acadêmicas, seus enunciados continuam produzindo ecos.

\section{Agradecimentos}

O autor agradece a agência de fomento CNPq, pela bolsa de doutorado.

\section{REFERÊNCIAS}

COURTINE, J.-J. Discurso, história e arqueologia. In: MILANEZ, N.; GASPAR, N. R. (ed.). A (des)ordem do discurso. São Paulo: Contexto, 2010.

COURTINE, J.-J. Discurso e imagens: para uma arqueologia do imaginário. In:

PIOVEZANI, C.; CURCINO, L.; SARGENTINI, V. (org.). Discurso, semiologia e história. São

Paulo: Claraluz, 2011.

COURTINE, J.-J. Foucault e a história da análise do discurso, olhares e objetos. In: FERNANDES, C. A.; CONTI, A.; MARQUES, W. (org.). Michel Foucault e o discurso: aportes teóricos e metodológicos. Uberlândia: EDUFU, $2013 a$.

COURTINE, J.-J. Decifrar o corpo: pensar com Foucault. Rio de Janeiro: Vozes, 2013b. 
COUTINHO, L. Hugo para principiantes. São Paulo: Devir, 2005.

COUTINHO, L. Muriel Total. São Paulo, 2014. Disponível em: http://murieltotal.zip.net/. Acesso em: 05 ago. 2020.

COUTINHO, L. Modelo vivo. São Paulo: Barricada, 2016.

COUTINHO, L. O Manual do Minotauro. 2020. Disponível em: http://manualdominotauro. blogspot.com.br/. Acesso em: 07 ago. 2020.

DELEUZE, G. O que é um dispositivo? In: DELEUZE, G. O mistério de Ariana. Lisboa: Nova Vega, 2015.

FOUCAULT, M. História da Sexualidade: o uso dos prazeres. 5. ed. Rio de Janeiro: Edições Graal, 1984. 2 v.

FOUCAULT, M. História da sexualidade: o cuidado de si. Rio de Janeiro: Edições Graal, 1985. 3 v.

FOUCAULT, M. História da sexualidade: a vontade e saber. Tradução Maria Thereza da Costa Albuquerque e J. A. Guilhon Albuquerque. Rio de Janeiro: Edições Graal, 1988. 1 v.

FOUCAULT, M. O sujeito e o poder. In: DREYFUS, H.; RABINOW, P. Michel Foucault: uma trajetória filosófica para além do estruturalismo e da hermenêutica. Tradução Vera Porto Carrero. Rio de Janeiro: Forense Universitária, 1995.

FOUCAULT, M. A ordem do discurso. Tradução Laura F. de A. Sampaio. São Paulo: Edições Loyola, 1999.

FOUCAULT, M. A arqueologia do saber. Tradução Luiz Felipe Bata Naves. 7. ed. Rio de Janeiro: Forense Universitária, 2007.

FOUCAULT, M. O corpo utópico, as heterotopias. São Paulo: n-1 Edições, 2013.

FOUCAULT, M. Ditos e escritos: genealogia da Ética, Subjetividade e Sexualidade. Tradução Abner Chiquieri. Rio de Janeiro: Forense Universitária, 2014. 9 v.

FOUCAULT, M. Histoire de la sexualité: Les Aveux de la chair. Paris: Gallimard, 2018. 4 v. 
GOMES FILHO, M. (Homo)sexualidades e Foucault: para o cuidado de si. Curitiba: Appris, 2016.

HENFIL. Fradim. 1-31. ed. São Paulo: Editora Codecri, 1971-1980.

HENFIL. Programa Vox Populi. [Entrevista cedida à] TV Cultura. Publicado pelo canal Kâmera Libre. 2016 [1978]. 1 vídeo (59 min). Disponível em: https://www.youtube.com/ watch?v=rzPVXdJw77E\&feature=youtu.be. Acesso em: 15 ago. 2020.

HENFIL. A volta da Graúna. São Paulo: Geração Editorial, 1993.

LAERTE-SE. Direção: Eliane Brum. Produção: Lygia Barbosa da Silva. [S.I.]: Tru3Lab; Netflix, 2017. 1 vídeo (100 min).

LEVY, P. O que é o virtual? Tradução Paulo Neves. São Paulo: Editora 34, 1996.

LIPOVETSKY, G.; SERROY, J. A estetização do mundo: viver na era do capitalismo artista. São Paulo: Companhia das Letras, 2015.

LUHMANN, N. A realidade dos meios de comunicação. São Paulo: Paulus, 2005.

MANOVICH, L. The Language of New Media. Massachusetts: MIT, 2001.

MAZZOLA, R. B. Análise do discurso e ciberespaço: heterotopias contemporâneas. 2010. Dissertação (Mestrado em Linguística e Língua Portuguesa) - Faculdade de Ciências e Letras, Universidade Estadual Paulista "Júlio de Mesquita Filho", Araraquara, 2010.

MILANEZ, N. As aventuras do corpo: dos modos de subjetivação às memórias de si em revista impressa. 2006. Tese (Doutorado em Linguística e Língua Portuguesa) Faculdade de Ciências e Letras, Universidade Estadual Paulista "Júlio de Mesquita Filho", Araraquara, 2006.

MILANEZ, N. Intericonicidade: funcionamento discursivo da memória das imagens. Revista Acta Scientiarum. Language and Culture, Maringá, v. 35, n. 4, p. 345-355, 2013.

MILANEZ, N.; GASPAR, N. R. (org.). A (des)ordem do discurso. São Paulo: Contexto, 2010.

PÊCHEUX, M. Semântica e discurso: uma crítica à afırmação do óbvio. Tradução Eni Orlandi et al. 4. ed. Campinas: Editora da UNICAMP, 2009. 
SILVA, G. C. da. O corpo em tirinhas e o discurso político-sexual no Brasil em 40 anos: entre A volta da Graúna e o Manual do Minotauro. 2019. Dissertação (Mestrado em Letras) Universidade Federal de Pernambuco, Programa de Pós-graduação em Letras, Recife, 2019.

SILVA, M. Rir das Ditaduras: os dentes de Henfil (Fradim-1971/1980). São Paulo: Intermeios; USP-Programa de Pós-graduação em História social, 2018.

SODRÉ, M. A Ciência do Comum: notas sobre o método comunicacional. Petropólis: Vozes, 2014.

TREVISAN, J. S. Devassos no paraíso: a homossexualidade no Brasil, da colônia à atualidade. 4. ed. rev. atual. e amp. Rio de Janeiro: Objetiva, 2018. 